\title{
A ERGONOMIA NA FORMAÇÃO SUPERIOR EM ARQUITETURA
}

\author{
FERRER, Nicole (1); \\ REITHLER, Luíza (2); \\ VARJÃO, Jakeline (3) \\ (1) FACIMED, Mestra em Projeto de Arquitetura \\ e-mail: nicferrer.arq@gmail.com \\ (2) FACIMED, Especialista em Gestão de Restauro \\ e-mail: luiza.reithler@gmail.com \\ (3) FACIMED, Especialista em Didática do Ensino Superior \\ e-mail: jakelinevarjaoarquitetura@gmail.com
}

\begin{abstract}
RESUMO
A Revolução Industrial reconfigurou a interação do homem com a realidade que o cerca. Em hipótese empírica, vê-se um aumento da complexidade no projetar o espaço graças à pluralidade dos parâmetros e condicionantes arquitetônicos no mundo contemporâneo. Assim, parte-se da premissa de que a Ergonomia do Ambiente Construído conseguiria interligar estas disparidades conceituais resultantes das grandes mudanças científicas e tecnológicas da sociedade ocidental. O presente artigo busca entender este potencial transformador ao ser inserido no contexto do ensino superior da arquitetura através de discussão dialética. Tal assertiva se apoia em fatos de experiências vividas em sala de aula, através da observação de interações variadas entre docentes e discentes.
\end{abstract}

Palavras chave: complexidade do projeto; ergonomia do ambiente construído; ensino superior em arquitetura.

\begin{abstract}
The Industrial Revolution reconfigured the interaction men have with the reality of their surrounding. In an empirical hypothesis, one sees an increase of the complexity in the space design due to the parameter plurality and architectonic determinants in the contemporary world. Thus, the premise here is that the Ergonomics of the Built Environment could interconnect these conceptual disparities resulted from great scientific and technological changes of Western society. The present paper seeks to understand this transforming potential when inserted in the context of higher education of architecture through a dialectical discussion. This assertion is based on facts of experiences lived in the classroom, as well as through the observation of varied interactions between teachers and students.
\end{abstract}

Keywords: project complexity; ergonomics of the built environment; higher education in architecture.

\section{INTRODUÇÃO}

Historiadores do espaço construído afirmam que uma grande contribuição da civilização grega no Mundo Clássico da Antiguidade, por volta do século $V$ a.C., foi a delimitação do território da arquitetura (PEREIRA, 2010). Isso significa a definição da amplitude do estudo, 


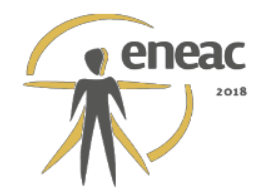

do panorama arquitetônico à que o projetista toma posse. Este panorama passa então pela manipulação dos elementos construtivos em função de suas necessidades com a intenção de modificar o espaço à sua volta. É o surgimento da arquitetura como ciência a ser estudada e analisada em separado das demais artes. É a arquitetura como um campo de investigação próprio e único.

Ao se separar a arquitetura do cânone da pintura e escultura e transformá-la em ciência, o arquiteto invariavelmente modifica sua forma de enxergar o processo construtivo. A arquitetura admitirá sua condição intrínseca de natureza artística que define qualificações para a obra edificada, dada a sua origem nas artes plásticas. Porém, há a necessidade primeira de uma ordenação com a intenção de se definirem conexões lógicas desta totalidade construída de partes - concretizadas em ambientes e/ou espaços - que se articulam entre si.

Dentro deste universo, os antigos gregos definiram a conceituação de antropomorfismo para se basear no processo projetual de seus grandes edifícios, principalmente de seus templos religiosos. É uma ideia que consiste na utilização do homem como parâmetro de medida para todas as coisas. O corpo humano passa a ser o centro e a medida do Universo, o que levou diversos estudiosos a olharem para as proporções do corpo a procura de referencial na modificação do espaço construído. Ao longo dos séculos, projetistas como Leonardo da Vinci, na Idade Humanista, e Ernst Neufert, na Idade Moderna, desenvolvem tais estudos, como referenciado nas imagens icônicas da Figura 1.

\section{Figura 1 - Esquema antropocêntrico renascentista, de Leonardo da Vinci (à esquerda), e moderno, de Ernst Neufert (à direita).}
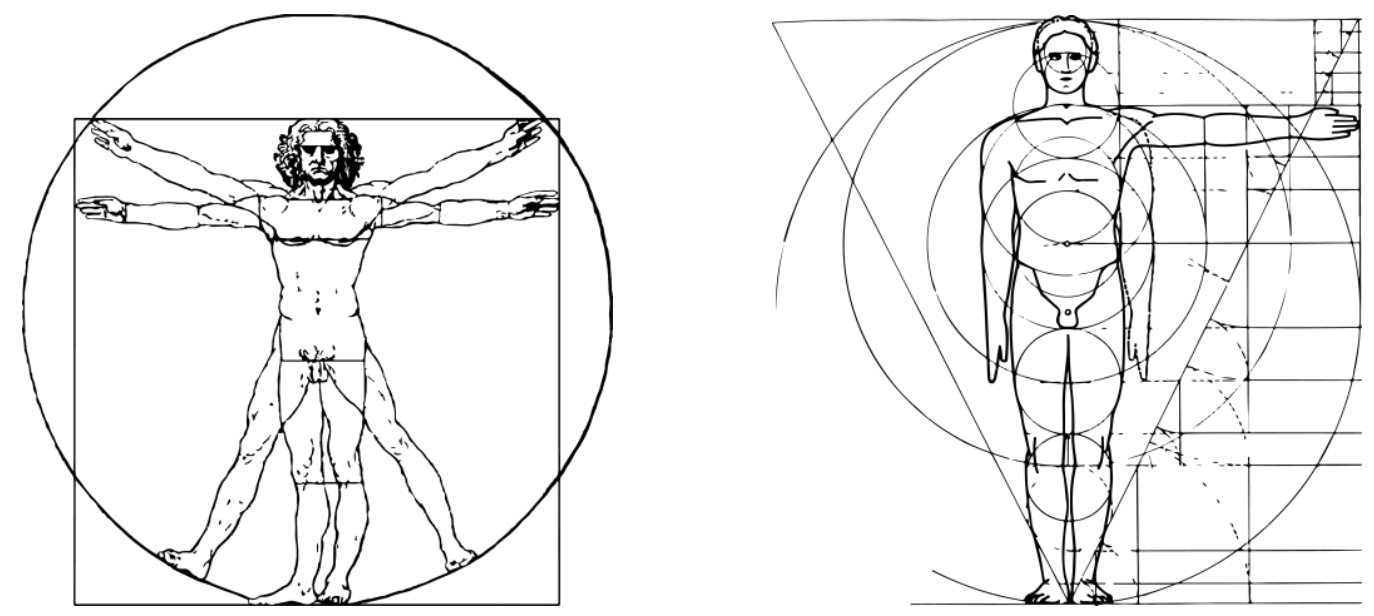

Pereira (2010) afirma que as considerações filosóficas do projetista Clássico mudam de orientação, deixando de olhar para o mythos a fim de se concentrar no logos. Ou seja, "se deixam de lado os problemas divinos e se foca no homem e no humano". Contudo, tais preceitos foram utilizados por esta sociedade como medidas de ordem e proporção, desenvolvendo uma arquitetura feita com o intuito de contemplação à distância, restringindoIhe o uso. Por mais que a escala humana fosse vista como o embasamento de beleza daquela sociedade, princípio básico da arquitetura grega, a mesma não conseguia enxergar o homem como ator do cenário construído interno. Além disso, indubitavelmente, a filosofia clássica grega de arquitetura foi uma das principais heranças da arquitetura ocidental contemporânea. Como diria o historiador da arquitetura Sigfried Giedion, "somos todos gregos".

Durante os 25 séculos que se seguiram, muitos estudos e descobertas foram feitas que transformaram o território da ciência do espaço construído. Contudo, sua base permanece a 


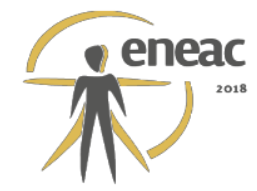

mesma, sendo os conceitos clássicos da Grécia e Roma Antigas revisitados de tempos em tempos pelos expoentes da arquitetura. O último século, mais especificamente, viu surgir a Arquitetura Moderna, que propôs métodos reducionistas e a organização do processo projetual como uma atividade direcional "top-down", ou seja, o arquiteto como definidor de todos os parâmetros do espaço (RIBEIRO e PRATSCHKE, 2005).

No entanto, atualmente, tais pensamentos vêm sendo reavaliados. Acredita-se na possibilidade de se inverter essa dinâmica através do processo de design como uma atividade coordenada por uma dinâmica "botton-up", com a estimulação da interatividade e da integração entre sujeitos, objetos e disciplinas no decorrer desse processo.

Segundo Butti (1998) apud Reis (2003), "a ergonomia do ambiente construído deve se ocupar de quem usará, que coisa será usada, mas principalmente onde virá a ser usada. Onde é o ambiente de destinação que deve ser analisado como lugar físico e sociocultural que condiciona a interação entre o homem e o objeto". Logo, se transpormos a tríade conceitual de sujeito, objeto e disciplina para usuário, ambiente e atividade, têm-se a base da Ergonomia do Ambiente Construído.

Ao utilizar-se a historicidade da arquitetura como ferramenta analítica, é possível colocar em perspectiva temporal e espacial as ações humanas em relação ao espaço construído. Desta forma, todas as coisas e atividades humanas tem um sentido dentro de seu contexto, configurando um conjunto de fatores determinantes da caracterização de uma época. Assim como disse o famoso arquiteto e urbanista Lúcio Costa, "arquitetura é a construção concebida com a intenção de ordenar plasticamente o espaço, em função de uma determinada época, de um determinado meio, de uma determinada técnica e de um determinado programa" (CORONA e LEMOS, 1972).

O espaço físico ao ser projetado busca garantir ao homem, através de um ambiente artificial, a proteção aos riscos do ambiente exterior, promovendo uma estrutura funcional onde as atividades humanas possam ser abrigadas. Estas atividades são determinadas a partir dos valores culturais da sociedade em que o edifício está inserido.

Deste modo, a também chamada Ergonomia Ambiental ultrapassa questões meramente arquitetônicas, forçando o projetista a olhar o espaço através do foco da adaptabilidade e conformidade do espaço às tarefas e atividades que nele serão desenvolvidas (VILLAROUCO, 2002). Para tanto, olhar um projeto como ergonomista é antever sua utilização, é conjugar condicionantes físicos, cognitivos, antropométricos, da acessibilidade, psicossociais e culturais, objetivando identificar variáveis passíveis de não atendimento pelo espaço proposto.

Logo, o presente artigo busca entender o potencial transformador da Ergonomia ao ser inserida no contexto do ensino superior da arquitetura através de discussão dialética, partindo do pressuposto de que os movimentos históricos ocorrem de acordo com as condições materiais da vida. Há dois séculos, a Revolução Industrial na Idade Moderna reconfigurou a interação do homem com a realidade que o cerca. Assim, parte-se aqui da premissa de que a Ergonomia do Ambiente Construído possui o potencial de interligar disparidades conceituais que acometem a disciplina de arquitetura devido às grandes transformações científicas e tecnológicas da sociedade ocidental. Como dito por Paulo Freire (1981), "o homem, como um ser histórico, inserido num permanente movimento de procura, faz e refaz constantemente o seu saber".

\section{ENSINO SUPERIOR EM ARQUITETURA NO BRASIL}

Em levantamento realizado pelo Ministério da Educação em dezembro de 2015 (ABEA, 2017), o Brasil conta hoje com 466 cursos de ensino superior em arquitetura dentre as 27 unidades da federação. São 210 cidades que formam diversos arquitetos a cada semestre. 
Em 2016, a Folha de S. Paulo realizou seu Ranking Universitário Folha - RUF, elencando as melhores universidades, escolas superiores e faculdades do país, públicas e privadas, classificadas de acordo com diferentes quesitos, como "Qualidade de Ensino", "Avaliação do Mercado" e nota no ENADE. Assim, a Tabela 1 a seguir mostra a realidade atual das matrizes curriculares nos 10 melhores cursos de arquitetura e urbanismo do país e as disciplinas relacionadas com a Ergonomia. Dentre as 10 universidades aqui estudadas, apenas 4 possuem disciplinas com ementas direcionadas ao estudo da Ergonomia do Ambiente Construído. Destas 4, todas são disciplinas optativas, o que significa que nem sempre são ofertadas pelo quadro de docentes.

Tabela 1 - Disciplinas de ergonomia nos 10 melhores cursos de arquitetura do Brasil.

\begin{tabular}{|c|c|c|c|}
\hline $1^{\circ}$ & Universidade Federal de Minas Gerais (UFMG) & optativa & $60 \mathrm{~h}$ \\
\hline $2^{\circ}$ & Universidade de São Paulo (USP) & optativa & $60 \mathrm{~h}$ \\
\hline 3은 & Universidade Federal do Rio de Janeiro (UFRJ) & optativa & $60 \mathrm{~h}$ \\
\hline $4^{\circ}$ & Universidade Federal do Rio Grande do Sul (UFRGS) & não consta no currículo & - \\
\hline $5^{\circ}$ & Universidade Presbiteriana Mackenzie (MACKENZIE) & não consta no currículo & - \\
\hline 6o & Universidade de Brasília (UnB) & optativa & $100 \mathrm{~h}$ \\
\hline $7^{\circ}$ & Universidade Federal do Paraná (UFPR) & não consta no currículo & - \\
\hline $8^{\circ}$ & Universidade Estadual de Campinas (UNICAMP) & não consta no currículo & - \\
\hline 99 & Universidade Federal de Santa Catarina (UFSC) & não consta no currículo & - \\
\hline $10^{\circ}$ & Universidade Federal da Bahia (UFBA) & não consta no currículo & - \\
\hline
\end{tabular}

Fonte: As autoras.

De acordo com Cervo e Bervian (2002), "a universidade brasileira evolui a grandes passos. Voltada anteriormente à transmissão do saber adquirido ou à conservação do patrimônio cultural do passado, orienta-se em nossos dias, sob pressão das mudanças constantes que o desenvolvimento impõe, à formação de profissionais de nível universitário". No entanto, ainda pelos autores, muitas medidas precisam ser tomadas junto aos alunos e professores a fim de que a academia corresponda adequadamente "às novas funções que the são impostas pelas novas necessidades culturais e econômicas".

É importante ressaltar que o ensino superior em arquitetura no Brasil completou 200 anos de existência em 12 de agosto de 2016. São apenas 2 séculos de história em que a profissão de arquitetura, uma das mais antigas do mundo ocidental, cresceu e expandiu no país. Durante esse tempo, houveram muitas mudanças no modo de ensinar, na forma de construir e até mesmo em como pensar a arquitetura, tanto no sentido individual do desenvolvimento das atividades no ambiente construído, quanto no sentido coletivo, com a organização das comunidades e centros urbanos. Os constantes avanços tecnológicos e intelectuais vividos nos séculos XIX e XX vêm transformando fundamentalmente o modo de vida das pessoas.

Assim, o intuito maior do espaço acadêmico é fomentar cada vez mais a noção de reavaliação de contextos e realidades, para que se consiga, com profissionais capacitados, transformar para melhor os espaços construídos que habitamos. Para tanto, é necessário disponibilizar à sociedade profissionais curiosos, em constante indagação quanto a realidade em que vivem. 


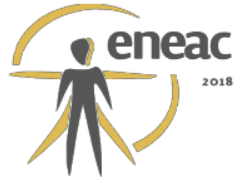

O acadêmico de arquitetura vive hoje em uma era de mudanças constantes, onde a complexidade dos problemas a ele propostos está em permanente crescimento. Dentre as habilidades exigidas deste profissional, está a capacidade de elaborar e gerenciar projetos de arquitetura, absorvendo as mudanças tecnológicas que ocorrem no âmbito do exercício profissional. Isso significa que o projetista necessita desenvolver um alto grau de adaptabilidade mental para desenvolver projetos únicos e individualizados, condizentes com o contexto em que este será inserido.

De acordo com Feiber e Merino (2011), o processo de concepção e elaboração de projetos arquitetônicos traz desafios quanto às novas possibilidades técnicas e velocidade de transformação, uma vez que é vivido o processo de globalização que desperta a necessidade de adaptação à realidade social. Para os autores, "os modos de produção dos projetos de arquitetura são por vezes questionados, bem como os modelos de pensar a edificação, e o próprio espaço arquitetônico quanto à capacidade de atender as necessidades e anseios atuais."

Novos paradigmas educacionais de multi, inter e transdisciplinaridade estão requalificando o ensino superior, além de trazer exigências de competências diversas. Há um elevado aumento da complexidade do pensamento e das dificuldades impostas no processo de aprendizagem da arquitetura, tanto a nível de concepção quanto tecnológico. Hoje, a sociedade capitalista avançada traz inúmeras problematizações do espaço construído como que em resposta aos problemas e desafios inerentes a ela.

No entanto, professores de projeto arquitetônico conseguem detectar uma transformação continuamente negativa em sala de aula nos últimos anos. O nível de ansiedade entre os alunos no momento inicial de concepção do projeto tende a aumentar, fazendo com que muitos estudantes percam a confiança ao se depararem com a folha em branco. Inevitavelmente, isso irá refletir na formação deste futuro profissional, uma vez que "quando o homem compreende a sua realidade, pode levantar hipóteses sobre o desafio dessa realidade e procurar soluções. Assim, pode transformá-la e o seu trabalho pode criar um mundo próprio, seu Eu e as suas circunstâncias" (FREIRE, 1983).

O docente tem de lidar com uma nova geração tão conectada com a mídia e as redes sociais, que a habilidade de filtragem das informações passa a ser um grande desafio. Surge então o diagnóstico de um conflito originado pela contradição entre princípios teóricos e fenômenos do cotidiano da vida acadêmica. Com tantas informações à disposição, o aluno tende a perder o foco no processo criativo da arquitetura.

Partir-se-á aqui do pressuposto empírico de que o obstáculo encontra-se na pluralidade dos parâmetros e condicionantes arquitetônicos, unificados através da investigação da forma, em uma contínua manipulação da plástica dentro de valores estéticos. Tal assertiva se apoia em fatos de experiências vividas em sala de aula, através da observação de interações variadas entre docentes e discentes.

Em uma esfera acadêmica ideal, pretende-se alcançar a instrumentalização do profissional de projeto de tal forma que as experiências vividas na academia iniciem a criação de um vocabulário referenciado em constante desenvolvimento, que passar-Ihe-á a segurança para os possíveis e diferentes projetos que se deparará na vida profissional. Contudo, a realidade lida com inúmeros jovens profissionais que não possuem a preparação necessária para enxergar o projeto de forma holística, uma vez que muitas vezes isso não lhes é ensinado na graduação. 


\section{reme $^{\text {remac }}$}

\section{O PAPEL DA ERGONOMIA DO AMBIENTE CONSTRUÍDO}

Com a criação do Conselho de Arquitetura e Urbanismo do Brasil (CAU/BR) através da Lei Federal no 12.378 de 31 de dezembro de 2010, as responsabilidades profissionais do arquiteto e urbanista brasileiro contemporâneo foram revisadas. A Resolução no 21/2012CAU/BR de 05 de abril de 2012, que dispõe sobre as atividades e atribuições profissionais, estabelece em seu artigo $2^{\circ}$ a atuação do profissional no campo do Conforto Ambiental, sendo usadas técnicas ao estabelecimento de condições climáticas, acústicas, lumínicas e ergonômicas, na concepção, organização e construção dos espaços, habilidades que recaem sob a égide da Ergonomia do Ambiente Construído.

Derivada do grego ergon [trabalho] e nomos [normas, regras, leis], a Ergonomia consiste em uma disciplina científica orientada para uma abordagem sistêmica de todos os aspectos da atividade humana. Para darem conta da amplitude dessa dimensão e poderem intervir nas atividades do trabalho, é preciso que os profissionais tenham uma abordagem holística de todo o campo de ação da disciplina, tanto em seus aspectos físicos e cognitivos, como sociais, organizacionais, ambientais, dentre outros. A aplicação da Ergonomia, enquanto uma abordagem interdisciplinar, no âmbito da atividade do trabalho, é essencial para o desenvolvimento de ambientes mais condizentes com as necessidades dos usuários e para a melhoria do desenvolvimento das tarefas (ABERGO, 2012).

Ao se determinar tantos elementos necessários à qualificação do espaço, percebe-se que desenvolver um ambiente ergonômico não se apresenta como uma tarefa simples. A diversidade de variáveis envolvidas nesse processo e a multiplicidade de fatores, que influenciam na adequabilidade ergonômica deste espaço, podem conduzir à necessidade de pesquisas em diversas áreas. Desenvolver esse olhar crítico e detalhista para entender, avaliar e modificar o ambiente construído é, acima de tudo, entender que o produto do fazer projetual destina-se a abrigar o homem, que com toda sua bagagem vivencial, representa 0 personagem central do ato de habitar (em sua significação mais ampla).

Historicamente, a formação do que hoje entendemos como Ergonomia se dá após a Segunda Guerra Mundial, apresentando-se como disciplina científica estruturada. Inicia-se formalmente o estudo do relacionamento entre o homem e seu trabalho, equipamento e ambiente. De natureza transdisciplinar, a Ergonomia lida com a aplicação de conhecimentos de anatomia, fisiologia, psicologia e, mais recentemente, arquitetura. Ela avalia e analisa as condições de desenvolvimento das atividades humanas, elencando fragilidades e possíveis soluções nos problemas surgidos desse relacionamento. Vidal (2018) corrobora que a Ergonomia, "com seu paradigma mecânico/termodinâmico do ser humano, foi o desaguar de atividades portanto milenares a partir de diversas disciplinas científicas", como apresentado na Tabela 2 abaixo.

Tabela 2 - Principais disciplinas formadoras do pensamento ergonômico clássico.

\begin{tabular}{|ll}
\hline Filosofia & Platão, Aristóteles \\
\hline Medicina & Ramazzini, Villermé, Tissot \\
\hline Físico-química & Lavoisier, Coulomb \\
Fisiologia & Amar, Chaveau, Marey \\
Engenharia & Da Vinci, Vauban, Jacquart \\
Organização & Taylor \\
\hline
\end{tabular}

Fonte: VIDAL, 2018. 


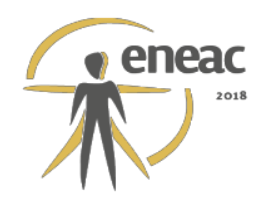

Lucio et al. (2010) afirmam que "ao mesmo tempo que o levantamento histórico da ergonomia no Brasil revela que uma investigação sobre ergonomia foi realizada no século XIX, com enfoque na antropometria, verificou-se que houve um longo período sem estudos nessa área. Somente a partir da década de 1970 pesquisadores de várias universidades brasileiras passam a introduzir a ergonomia no escopo dos estudos de diversas áreas do conhecimento". Isso mostra a natureza jovem que a disciplina apresenta no âmbito acadêmico brasileiro.

Ainda pelos autores, sabe-se que "a pesquisa em ergonomia vem se consolidando no país, porém ainda foi pequena a quantidade de livros produzidos no Brasil até o início da primeira década do século XXI. A razão dessa pequena produção de livros por autores brasileiros está relacionada ao fato de que efetivamente as pesquisas em ergonomia são recentes no país, visto que o primeiro trabalho publicado data de 1973."

No entanto, o que se vê hoje na arquitetura é a aplicação de normativas de acessibilidade como sistemas de "check-list" que o projetista deve garantir, sem pensar no processo projetual de conceber o espaço. Para muitos egressos dos cursos de arquitetura, Ergonomia se restringe a aplicação dos parâmetros disponibilizados na norma técnica de acessibilidade, a NBR 9050. Basta inserir uma rampa, um elevador ou um piso tátil no projeto, que pode-se garantir sua acessibilidade.

A inserção de metodologia ergonômica no processo de ensinar a lidar com o espaço construído apresentar-se-ia então como ferramenta de empoderamento do profissional de arquitetura no pensar do espaço construído, com a valorização do humano como foco central do ambiente. Desta forma, o aluno perceberia a arquitetura, o valor e a conectividade dos usuários com a realidade em que estão inseridos, além de manter em foco as possíveis tarefas que ali se viriam a desempenhar. Assim, quebrar-se-ia com o paradigma do estrelismo do profissional de arquitetura, popularmente denominado "starchitect" (junção das palavras em inglês "star" e "architect", designando o arquiteto estrela, famoso). O objetivo da concepção espacial seria atingido então através da priorização do que o outro quer e precisa no projeto, e não um significado estético e/ou estilístico.

Utilizar a ergonomia como meio de humanização do projeto reafirma os preceitos clássicos do homem como foco no despertar da arquitetura como ciência. Como concebido por JeanNicolas-Louis Durand na École des Beaux-Arts de Paris no século XIX, é possível considerar a arquitetura de maneira pragmática e utilitária, onde se "reconsidera a utilitas [função, uso] vitruviana e faz dela o fim da arquitetura, e de seus meios, os quais chama de conveniência e economia, entendendo por conveniência a solidez, o saudável e a comodidade - a antiga firmitas [forma, estrutura] -, enquanto a simplicidade, a regularidade e a simetria são os atributos da economia. E é a composição que resolve as duas ao mesmo tempo." Ou seja, ao se enfatizar a inserção humana no espaço através da análise de suas funções e usos no ambiente, configurando-o especificamente para essa finalidade, 0 equilíbrio estético e plástico da composição vêm como consequência natural dessa dinâmica.

\section{NORMATIZAÇÃO DO PROCESSO PROJETUAL}

A arquitetura em sua atividade de projeto é um exercício propositivo de espaços específicos, dotados de qualidades intrínsecas, definidas em seu desenho ou qualquer outra mediação de linguagem, modelos digitais ou físicos. O espaço projetado e específico se refere a uma matéria, representa-a enquanto mediação de uma topografia, reduzida em escala à representação projetiva. Todo projeto parte então de uma precedência, uma base ontológica que antecede as operações propositivas. Estas proposições conferem forma e atributo 


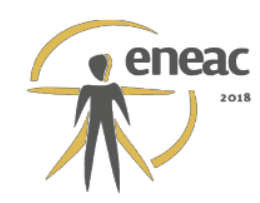

(qualidade) a esse ser. A partir da representação de uma matéria precedente, o arquiteto propõe o espaço arquitetônico, que qualifica e materializa um complexo de intenções e atributos, modificando o conjunto dessas precedências (ABASCAL e ABASCAL BILBAO, 2010).

A escolha pelo arquiteto de uma linguagem ou expressão para sintetizar essas relações qualitativas e quantitativas exige uma sintaxe própria, estabelecendo os limites de seu campo de saber. As manifestações culturais da prática projetual são matéria de análise histórica, um instrumento de exploração da especificidade do campo da Arquitetura.

A operação de articulação de múltiplas determinações de qualidade e quantidade confere ao arquiteto o papel de coordenador ou sujeito da síntese do processo de projeto. Essa natureza processual, que conforma e acomoda à sintaxe, produz um conjunto de determinações ou qualidades. É um gesto de articulação de outros saberes ou conteúdos, de natureza técnica

As demais ciências ou engenharias se subordinam a essa coordenação arquitetônica, e o projeto é o meio articulador das relações com a cidade (urbanismo), com os materiais, as ciências físicas (instalações elétricas e hidráulicas), etc. O projeto é, então, um ato operativo que estabelece relações entre saberes aparentemente descontínuos, a partir de uma intencionalidade do sujeito arquiteto, que o articula (ABASCAL e ABASCAL BILBAO, 2010). Como dito por Pereira (2010), "a delimitação do território de um tipo de arte requer um conjunto de regras objetivas, análogas às leis da natureza, que definirão o valor de cada obra".

As escolas de ensino superior de arquitetura e urbanismo ensinam os estudantes a respeitar os parâmetros normativos especificados em diversas legislações. O que é algo extremamente válido, uma vez que nivela a qualidade no espaço construído. No entanto, este nivelamento é feito por baixo, visto que esses parâmetros são o mínimo esperado de uma obra arquitetônica. Falta o estímulo para se enxergar o espaço construído como um sistema complexo que deve ser visto de forma completa, em todos os níveis e variáveis de ocupação. Muitas escolas esquecem de ensinar o futuro arquiteto a ver o homem como ator modificador do espaço projetado pelo profissional de arquitetura. Desta forma, é imprescindível considerar a variabilidade das atividades na etapa de concepção projetual onde, muitas vezes, esta população nem sempre é completamente entendida.

Béguin (2007) apud Feiber e Merino (2011) corrobora que projetos de arquitetura devem ser feitos "levando em consideração a necessidade de serem pensados, simultaneamente, o objeto produzido e a atividade que envolve o uso desse objeto". Isso significa que o processo de apropriação do espaço pelo usuário pode se dar pela "inovação do uso do objeto a partir do desenvolvimento de técnicas e estratégias baseadas em dispositivos já existentes, ou pela modificação e transformação do objeto em uma construção própria do trabalhador". Logo, o papel do arquiteto passa a ser o de articulador entre concepção e realidade, a fim de otimizar a realização das atividades necessárias.

Feiber e Merino (2011) por sua vez, afirmam que "não existe uma única solução para uma demanda particular, da mesma forma que não existe um único ponto de vista para as mesmas circunstâncias de trabalho". Esta premissa é observada todos os dias em sala de aula nas disciplinas de arquitetura, uma vez que cada futuro profissional desenvolve uma solução para a mesma problematização proposta.

\section{CONCLUSÃO}

A Ergonomia do Ambiente Construído não é uma disciplina que estuda apenas a inclinação da rampa ou percurso da cadeira de rodas. Tampouco se restringe à definir alturas de mesas ou larguras do vão livre de portas. Há o potencial ainda não explorado de se conectar 


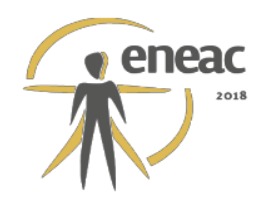

a Ergonomia ao processo projetual, onde ambos podem andar juntos e trabalhar em paralelo durante todo o desenvolvimento de concepção. Tal postura poderia vir a trazer uma maior adaptabilidade do projetista às novas problematizações que lhe são apresentadas na vida profissional, como também garantiria a qualidade do espaço projetado.

O desafio se encontra na busca de caminhos que estruturam a prática arquitetônica como uma prática do design da "interação". A complexidade contextual deixa de ser um obstáculo e passa a ser vista como uma espécie de guia no projeto do espaço construído. Compreende-se assim que ao trabalhar com a complexidade "o arquiteto pode ampliar sua visão do design considerando este, mais como processo que como produto, e uma concepção deste como campo de relações em lugar da organização de objetos" (RIBEIRO e PRATSCHKE, 2007).

Uma vez que o ambiente é consequência direta da manipulação do espaço natural pelo homem, independentemente deste espaço ser interno ou externo, o homem consiste na causa primária deste ambiente. Logo, extrapola-se esta assertiva ao homem sendo a causa primária da própria arquitetura. A Ergonomia se configura, então, como ferramenta em potencial para unificar o processo de projetação mais complexo que se apresenta na sociedade do século XXI.

\section{REFERÊNCIAS BIBLIOGRÁFICAS}

ABEA, Associação Brasileira de Ensino de Arquitetura e Urbanismo. Cursos de Arquitetura e Urbanismo no Brasil. Disponível: <http://www.abea.org.br/?page_id=11>. Acesso em: 23/09/2017.

ABASCAL, E. H. S.; ABASCAL BILBAO, C. Arquitetura e ciência: Reflexões para a constituição do campo de saber arquitetônico. Arquitextos, São Paulo, ano 11, n. 127.02, Vitruvius, dez. 2010. Disponível em: <http://www.vitruvius.com.br/revistas/read/arquitextos/11.127/3688>. Acesso em: 10/08/2017.

ABERGO, Associação Brasileira de Ergonomia. O que é Ergonomia. Disponível em: <http://www.abergo.org.br/internas.php?pg=o_que_e_ergonomia> Acesso em: Março de 2012.

Associação Brasileira de Normas Técnicas. NBR 9050: 1994. Acessibilidade de pessoas portadoras de deficiências a edificação, espaço mobiliário e equipamentos urbanos. Associação Brasileira de Normas Técnicas. Rio de janeiro: ABNT, 1994.

BRASIL. Lei de Diretrizes e Bases da Educação Nacional. Lei número 9394, 20 de dezembro de 1996.

BRASIL. Lei no 12.378 de 31 de Dezembro de 2010. Regulamenta o exercício da Arquitetura e Urbanismo; cria o Conselho de Arquitetura e Urbanismo do Brasil - CAU/BR e os Conselhos de Arquitetura e Urbanismo dos Estados e do Distrito Federal - CAUs; e dá outras providências. Diário Oficial da União, Brasília, 31 dez. 2010.

CAU/BR, Conselho de Arquitetura e Urbanismo do Brasil. Resolução n ${ }^{21}$, de 5 de abril de 2012. Brasília: CAU/BR, 2012.

CERVO, A. L.; BERVIAN, P. A. Metodologia científica. 5. ed. São Paulo: Prentice Hall, 2002.

CORONA, E.; LEMOS; C. Dicionário da Arquitetura Brasileira. São Paulo: Edart, 1972, p. 54.

FEIBER, F.N.; MERINO, E.A.D. $O$ ensino de projetos arquitetônicos e a ergonomia cognitiva. Revista Thêma et Scientia. v. 1, n. 1. 2011.

FREIRE, P. Educação e mudança. 8.ed. Rio de Janeiro: Paz e Terra, 1983. 


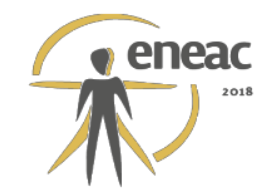

FREIRE, P. Educação como prática da liberdade. Rio de Janeiro, Paz e Terra, 1981.

LUCIO, C. do C.; ALVEZ, S.A.; RAZZA, B.M.; SILVA, J.C.P. da; PASCHOARELLI, L.C. Trajetória da ergonomia no Brasil: aspectos expressivos da aplicação em design. In: SILVA, J.C.P..; PASCHOARELLI, L.C. (Orgs) A evolução histórica da ergonomia no mundo e seus pioneiros [online]. São Paulo: Editora UNESP; São Paulo: Cultura Acadêmica, 2010. 103 p. ISBN 978-85-7983-120-1

PEREIRA, J. R. A. Introdução a história da arquitetura, das origens ao século XXI. Porto Alegre: Bookman, 2010.

REIS, A. T. da L.; LAY, M.C.D. Avaliação da qualidade de projetos. Ambiente Construído, Porto Alegre, v. 6, n. 3, p. 21-34, jul./set. 2006.

RIBEIRO, C.; PRATSCHKE, A. Transdisciplinaridade e complexidade na arquitetura. In: II Congresso Mundial de Transdisciplinaridade, 2005. Disponível em: $<$ http://www.nomads.usp.br/pesquisas/cultura_digital/complexidade/pdf/ARTIGOS/Clarissa\%20Ribeiro \%20e\%20Anja\%20Pratschke.pdf>. Acesso em: 12/08/2017.

VIDAL, M.C. Apostila: Introdução a Ergonomia. 35 p. In. Universidade Federal do Rio de Janeiro. GENTE/COPPE Grupo Integrado de Ergonomia e Novas Tecnologias. Disponível em: <http://www.ergonomia.ufpr.br/Introducao\%20a\%20Ergonomia\%20Vidal\%20CESERG.pdf>. Acesso em: 15/02/2018. 